nourishment was given by the rectum. Nothing but ice or water in very small quantities was given by the mouth except on the fourth day, when he took a teaspoonful of chicken broth every hour. On the fifth day the same quantity of milk and soda-water was allowed, and the nutrient suppositories and enemata wore discontinued, as he had diarrhœa. On the seventh day his diet was improved, and he was allowed beaten-up eggs, broth, milk, jelly, and a little claret. Morphia was used subcutaneously to give sleep and quiet irritability, and opium had to be given by the rectum for his diarrhoea.

The patient has enjoyed better health since the operation than he has done for years. His bowels act in a normal manner, which he believes they have not done for fifteen years, and he has gained in weight.

Remarks.-Although the impacting gall-stone in this case was large, there are many larger on record, which have been either passed per anum, discharged through fistulous openings externally, or found in the intestines after death. The chief interest of the case lies in its successful treatment by surgical operation. It is probably the first case on record of recovery after removal of a gall-stone from the intestine by incision, the intestine being sutured and returned to the peritoneal cavity. It is probable that the so-called "attack of inflammation of the bowels" fifteen years previously marked the time at which the gall-stone gained entrance to the intestine by ulceration, and that from this period there was an ever-increasing obstruction to the passage of fæces, until an attack of intestinal irritation produced sufficient swelling of the mucous membrane to make the obstruction complete. From the appearance of the stone, with a facet on its upper end, we conclude there is still another, though smaller calculus, most probably in the gall bladder, or it may be in the intestines. During the diarrhoea which succeeded to the operation careful watch was maintained, but no concretion was discovered in the motions. The symptoms that fortunately gave a correct indication of the locality of the obstruction were, first, the situation of the pain always near the middle line; secondly, the absence of any considerable distension of the abdomez; thirdly, the very early occurrence of romiting in the case; fourthly, the scantiness of the urine; fifthly, the fact that two or three pints of fluid could be retained as an enema without unduly distending the rectum. The case furnished an excellent test of the value of Lembert's suture; it kept the intestinal wound, which was two inches in length, satisfactorily closed, although there were six actions of the bowels in the first four days, and on the sixth day there was an attack of diarrhoea. In the after-treatment we adopted a plan of dieting which Mr. Smith had derived from a knowledge of Mr. Lawson Tait's practice in cases of abdominal operation. For forty-eight hours the patient was kept almost entirely without food or fluid of any kind, and although he suffered severely from thirst, yet we believe his recovery without any serious symptoms was largely due to this regimen.

\section{SUPRA-PUBIC LITHOTOMY : A HISTORICAT SKETCH.}

By CHARLES W. DULLES, M.D.,

SURGEON TO OUT-PATIENTS IN THE HOSPITAL OF THE UNIVERSITY OF PENNSYLVANIA, AND IN THE PENNSYLVANIA HOSPITAL IN PHIXADELPHIA.

THE operation of supra-pubic lithotomy was first performed in France in 1551, under the stress of necessity. At this time, Franco, after he had failed to remove a stone from a child of two years, by cutting "on the gripe," made an incision through the abdominal wall and removed the calculus in this way. But he was far from recognising the value of the invention he had been driven to, and did not advise imitation of his example. Nearly thirty years later, Rousset, as a result of studies in regard to Cæsarean section, came to believe that Franco's act of desperation was worthy of deliberate adoption as a method of lithotomy, and, in a work on the Cæsarean operation, described the details he thought advisable, dofended the theoretic merits of the method, and answered objections he supposed might be raised-objections which, in fact. were afterwards raised. Rousset never bad the opportunity to perform the operation, the death of Henry III. depriving him of the hope of obtaining permission to practise it upon a criminal-a favourite way of experimenting in those days. Nevertheless, to Rousset, and Rousset alone, belongs the credit of first seriously adrocating the removal of stone from the bladder by incision above the pubes. Franco's act was unpremeditated, and the value of its results unrecognised by him. Rousset saw what good use it might be turned to, and his name should never be left out of any account of supra-pubic lithotomy. Early in the seventeenth century Fabricius Hildanus did this operation but strongly dissuaded others from attempting it. Nevertheless, contemporary writings would indicate that it continued in use in France much oftener that can be established from recorded cases.

It was not till near 1700 that the operation seems to have crossed the British Channel, the first recorded operation on the western side being done by Proby, in Edinburgh, to remove from a woman's bladder an ivory bodkin which she declared she had swallowed by accident. In 1718 the method was demonstrated by James Douglas before the Royal Society of London. The next year his brother, John Douglas, performed it successfully, and in 1820 he published a work upon it called "Lithotomia Douglasiana." Deschamps accuses him openly of having borrowed his idea from Rousset's book, which both the brothers denied that he had ever seen. However this may be, the operation at once secured adherents and was employed by a number of English surgeons both in hospitals and in private practice. The most noted operator at that time was Cheselden, the perfector of the left lateral operation, often called by his name. He followed Douglas's method in'ten cases. All of his patients recovered except one, who died of dinrrhoea and fever due to an indiscretion after he was able to go about. Cheselden finally abandoned this method because others cut the peritoneum and burst the bladder in attempting to distend it. Other operators in England did the supra-pubic operation about this time; so that for a while it seemed to have more acceptance here than in the land of its origin. In Holland it was employed by Sermes at least sixteen times, in five of which death followed, and the euthorities forbade his using it any more.

In 1758 , the scene of greatest activity was transferred to France, through the energy and success of Frère Côsme, who did a hundred operations of this kind from 1758 to 1781 , and lost but nineteen of his patients. Côsme first used a counteropening through the perineum to secure drainage, though this was first suggested by Palluci in 1750 , together with \& recommendation to close the wound with sutures. Côsme, however, has undisputsd claims to the invention of the sonde-ì-dard. Scarcely had Côsme left the world when Souberbielle began a series of operations in 1796 , which, continuing until 1843. when the operator was eighty-eight years old, numbered in all 115. Thus we see that two French surgeons have contributed 215 , or about one-third of all the cases recorded up to 1881 .

With the early part of the present century the well-known names of Scarpa, Vacca Berlinghieri, Dupuytren, Home, Dzondi, Amussat, Lisfranc, and Civiale, in Kurope, and of Gibson, Carpenter, and McClellan in America, enter the list of those who used the supra-pubic operation. All, however, practised it without preference, if Amussat be excepted. The prevailing opinion had come to be adverse to this operation, its dangers being exaggerated and the safety of perineal lithotomy being considered all that could be expected. One author copied another in condemning it, and it looked as as though it might soon fall into oblivion. In I850 Dr. G. Murray Humphry, of Cambridge, Fngland, published an account of a successful operation done by him in 1818 , together with a table of 104 cases, which has been the basis of most English statistical estimates until after 1875. This collation of statistics was not calculated to give any great confidence in the supra-pubic method, and the. English opinion has continued until recently to be in the main unfavourable to it.

In Germany, on the other hand, there began, at about the same time, a decided revival of interest in this operation. This was principally attributable to the influence of Prof. Günther, of Leipsic, who collected 260 cases and printed their details in an able monograph entitled "Der hohe Steinschnitt seit seinem Ursprunge bis zu seiner jetzigen Ausbildung" (Leipzig, 1851). His presentation of the subject, backed by his own successful employment of it, caused the opinions of his countrymen to be more favourable than those of any other nationality, while in Austria and Hollard his 
influence has also been marked. Strange to say, there is scarcely an allusion to this, the best monograph ever published on this subject, by any English or American author before 1875, up to which time every one of these authors referred to Humphry's table for their estimate of the merits of supra-pubic lithotomy. In England and Ameriea the operation was but rarely done and hardly ever heard of. Here, however, occasionally a surgeon was driven to it because of failure to extract a stone through the perineum. Wrom 1853 to 1857 , Dr. Willard Parker, of New York, influenced by German teachings, cut four women and one man in this way, and then gave the method up. The late Dr. Krackowitzer, of New York, whose name betrays his nationality, wrote me in 1874 that he had done this operation six times since 1859. Dr. Guido Bell, of Indianapolis, a German, has done it four times since 1867 without a death. Dr. Jacobi, of New York, another German it will be observed, has done it seven times since 1868. But with these exceptions the operations of no surgeon in America had, before 1875, exceeded two or three in number.

In 1874, I was one day present at an operation of lithotomy in which several skillful surgeons laboured long and hard to extract a calculus by the usual lateral operation of Cheselden. Three hours were occupied in fruitless attempts to remove the stone entire, or to crush it. At the end of this time it was suggested to try the "high operation" before giving the attempt up. No one present had ever seen this method practised; but the operator, being a good anatomist, had no difficulty in carrying it out; and in about tbree minutes the bladder had been opened above the pubes, the stone-which was as large as a pullet's egg-had been easily removed, a fow stitches had been inserted, and the patient was taken back to his bed. The sight of this operation led me-then a student of medicine - to a study of the history and merits of the supra-pubic operation of lithotomy, which covered a period of a year, and led to the publication of a paper on the subject, which was printed in the American Journal of the Medical Sciences, July, 1875. In this paper there is an abstract of the contents of an inaugural thesis, which embraced a historical sketch of the "high operation" from the days of Franco to 1875 , and an analysis of the facts gathered from a table of statistics containing reports of 478 cases. The analysis showed the results of supra-pubic lithotomy, by themselves and compared with those of the lateral (perineal) operation. One of the most interesting features of the analysis was the demonstration of the fact that supra-pubic lithotomy gives as good results as lateral lithotomy for calculi weighing between one and two ounces, and better results for calculi above two ounces in weight. Opon theoretical grounds, it was contended in this paper that the supra-pubic operation is preferable to the lateral; and it was asked: "If these, then, be the facts, is not this method deserving of more attention and a fairer trial than it has yet had? Does it not, theoretically and by its actual results, commend itself to the candid judgment as a method which offers sufficient probability of success, if rightly and carefully executed, to lead to its application in other cases than the most desperate? For many years it has been assigned this position of a 'forlorn hope.' Shall it not be some day placed where, with less disastrous obstacles, it may win success without having its victories made to seem like defeats because of the losses rendered inevitable by the field to which it has been limited ?"

From the time when this hope was expressed until the present, I have not ceased to follow with deep interest the history of supra-pubic lithotomy. For some years I continued to collate and analyse its statistics, so that, in 1881, Thad collected and studied the reports of 636 operations by this method, with results practically identical with those published in 1875. Especially gratifying was it to one who had faith in the merits of supra-pubic lithotomy to note how it was gaining the confidence of surgeons all over the world, so that the operation was coming into more and more general use. A study of its history by epochs shows that it was practised in the sixteenth century only once; in the seventeenth only seven times; in the eighteenth 191 times; in the ifrst half of the nineteenth 237 times; and in the next thirty years more than 200 times. At this time (1887) the whole surgical world seems convinced of the merits and practicability of this method. This state of affairs can be traced to several things: one, the steady defence of the method by those who believed in it; another, the demonstration of its merits by the study of a sufficiently large number of cases; another-and most important factor-the proposition of
Professor Petersen to facilitate access to the bladder by distension of the rectum ; ${ }^{1}$ another, the zeal with which it has been championed and practised lately in Paris by Monod, Guyon, Perier, and other surgeons; and, lastly, the conversion of Sir Henry Thompson, who, after long denying its claims, has become one of its most enthusiastic propagandists. At the present day, then, supra-pubic lithotomy may be said to be on the very crest of the wave of popularity. It is even necessary, I think, for those who have believed most patiently and consistently in its merits, to raise a voice of caution lest it suffer by being overrated, even as it so long suffered by being underrated. After thirteen years of study of this method and an analysis of over 700 operations, 1 have come to the conclusion that a temperate view of the subject will lead to the conviction that the supra-pnbic operation deserves to rank above all other methods of lithotomy for stones of large size, and that its applicability to any case should be carefully discussed before deciding to cut through the perineum.

Chronological Summary.-1551: Franco did the first operation. 1580: Rousset described and advocated it. 1694: Proby did the operation successfully. 1698: Solengius distended the bladder with air. 1719: Douglas established it in England; Bamber injected the bladder after opening the abdomen. 1724: Sermes made a cut in the perineum to introduce the sound. 1739: Clelland proposed a peculiar sound. 1750: Pallucci proposed a perineal incision for drainage, and suture of abdominal wound. 1758: Côsme used the sonde-á-dard and perineal counter-incision; he also attempted suture of the wound. 1773: Le Blanc said to have operated "en deux temps." 1783: Aitken proposed dividing the "share-bones." 1785: Espiaud placed his patient in a sitting posture after operation. 1800: Souberbielle argued that the catheter was not indispensable for drainage. 1826: Pinel Grandchamp proposed suture of the bladder-wound. 1828: Baudens operated with bladder undistended. 1829: Tanchou practised constant irrigation of bladder and wound. Geo. Bell dilated a fistula to remove a stone, and proposed this as a method. 1832: Vidal de Cassis proposed the method "en deux temps." 1841 : Nélaton did first operation "en deux temps." 1843: Felpeau opposed using sutures. 1850: Delery applied sulphate of iron and powdered camphor to wound to prevent septic absorption. 1851: Günther published his monograph. 1854: Baudens sewed up bladder after extraction of bullet. 1857: Bruns practised suture of the bladder wound. 1871: Listerism used by Lister. 1874: Anger recommended use of thermo-cautery. 1875: Trendelenburg proposed placing patient on abdomen for drainage. Dulles reported analysis of 478 cases, and adrocated general adoption. 1879 ; Flury published statistics of ninety-three cases. Van Godœver advocated general adoption. 1880: Petersen recommended distension of the rectum to raise distended bladder out of pelvis. 1881 : Langenbuch proposed "sectio alta plastica."

\section{ON ECZEMA AND PSORIASIS.}

\section{BY A. S. MYRTLE, M.D. EdiN.}

ForTY years' experience with any class of patients should afford many and valuable opportunities of comparative observation, not only as to the results of one's own practice, but as regards that of many of the most distinguished of the profession. Such has been my lot; and it is after having treated thousands of cases of eczema and psoriasis-cases, many of them at least, which had been seen by the best specialists, - tried every remedy, from Holloway's ointment to cuticura, and visited the most famous watering places in Europe, without securing much benefit, that I venture to lay the lessons I have been taught and the conclusions I have arrived at before the readers of THE LANCET. I shall assume that they are all as familiar with the symptoms and varieties of both affections as $I \mathrm{am}$. As far as varieties go, I may at once say I recognise only eczema and psoriasis the forms they take are practically of no importance, however imposing they look on paper. Everyone will admit that both are becoming more and more common ; as a proof of this I need only point to the rapid growth of dermato-

1 This plan may have been suggested by the experiments of Dr. Garson of Edinburgh, which were reported to the Congress of German Surgeons by Prof. Braune. 